\title{
Effects of intensive rice production practices on avian biodiversity in Southeast Asian managed wetlands
}

\begin{abstract}
Rice fields are common throughout the agricultural landscape of Southeast Asia and sustain various bird species. These birds can provide ecosystem services, such as pest control, that improve agricultural yields whilst minimising the use of agrochemicals. This study quantified avian biodiversity in rice production landscapes during three farming stages in Peninsular Malaysia. In Malaysia, rice fields can be an important habitat for migrating birds due to Malaysia's position on the East-Asian-Australasian Flyway. We determined bird abundance, species richness, and composition in rice field landscapes and compared these during different stages of rice growing. Wetland and terrestrial birds were counted in rice fields using the point-count method. Sixty sampling points were randomly established in three locations, from which 3447 individual birds of 46 species and 26 families were recorded. There was a significant difference in total bird abundance and species richness between the three different stages of rice growing. The growing stage supported greater bird abundance and species richness compared to the pre-harvest and post-harvest stages. Rice-growing provides temporary habitats to different bird species in this managed aquatic landscape. This implies the presence of abundant food, such as small fish and amphibians. The evidence from this study suggests that biodiversity-friendly agricultural practices should be implemented to improve habitat quality for birds in rice production landscapes.
\end{abstract}

Keyword: Abundance; Bird; Composition; Conservation; Rice fields; Species richness 